\title{
Germán Rey: \\ a política tradicional não \\ é suficiente, a cultura e as novas mídias podem ser espaços de resistência
}

\author{
Roseli Fígaro \\ Professora associada na Escola de Comunicações e Artes, professora do Programa de Pós-graduação em \\ Ciências da Comunicação da Universidade de São Paulo (USP). Coordenadora do Centro de Pesquisa \\ em Comunicação e Trabalho (CPCT). Diretora editorial da revista Comunicação Ė Educaşão. \\ E-mail: figaro@uol.com.br
}

Resumo: Comunicação \& Educação entrevista Germán Rey Beltrán, intelectual colombiano cuja trajetória está vinculada aos estudos de comunicação e cultura na América Latina. Germán Rey é coordenador da Cátedra Garcia Marquez de Jornalismo no Centro Internacional de Estudios Superiores de Comunicación para América Latina (CIESPAL). Estudou psicologia na Universidade Nacional da Colômbia, com doutorado em Psicologia na Universidade Complutense de Madrid. Participou do projeto "Economia e cultura" do acordo Andrés Bello (Secretaria Ejecutiva del Convenio Andrés Bello e Centro Regional para el Fomento del Libro en América Latina y el Caribe) coordenando o tópico "indicadores sociais e culturais". Foi assessor do Ministério da Cultura da Colômbia em pesquisas relacionadas às áreas de comunicação, cultura, gestão cultural e indústrias culturais. Por essa mesma instituição, coordenou e editou o Manual de Políticas Culturales (2009). Foi professor na Pontifícia Universidade Javeriana, na Universidade dos Andes e na Universidade Nacional da Colômbia (todas em
Abstract: Comunicação \& Educação interview with Germán Rey Beltrán, Colombian scholar whose trajectory is associated with studies of communication and culture in Latin America. Germán Rey is the coordinator of Cátedra Garcia Marquez of Journalism at Centro Internacional de Estudios Superiores de Comunicación para América Latina (CIESPAL). He studied Psychology at the National University of Colombia, with a doctorate in Psychology from Universidad Complutense of Madrid. He participated in the project "Economy and culture" of the Andrés Bello agreement (Secretaria Ejecutiva del Convenio Andrés Bello and Centro Regional para el Fomento del Libro en América Latina y el Caribe) coordinating the topic "social and cultural indicators." He worked as adviser at Colombia's Ministry of Culture in researches related to the fields of Communication, Culture, Cultural Management and Cultural Industries. At this same institution, he coordinated and edited the Manual de Políticas Culturales [Cultural Policies Manual] (2009). He was a professor at Pontifícia Universidade Javeriana, at Universidade dos Andes and at the National University of Colombia (all of 
Bogotá) nas áreas de comunicação, jornalismo e estudos culturais. Atualmente é professor no curso de Mestrado em Desenvolvimento e Cultura da Universidade Tecnológica de Bolívar (Cartagena das Índias, Colômbia). Publicou, entre outros livros, Oficio de equilibrista, 21 casos periodísticos, Los ejercicios del ver: hegemonía audiovisual y ficción televisiva, com Jesús Martín-Barbero; Industrias culturales, creatividad y desarrollo, Balsas y Medusas, sobre política nas mídias, e Desde las dos orillas, sobre o direito à informação.

Palavras-chave: Germán Rey; cultura; comunicação; jornalismo; mídias digitais. them in Bogota) in the fields of Communication, Journalism and Cultural Studies. $\mathrm{He}$ is currently a professor in the Master's Program in Development and Culture of Universidad Tecnológica de Bolívar (Cartagena das Índias, Colombia). He published, among other books, Oficio de equilibrista, 21 casos periodísticos, Los ejercicios del ver: hegemonía audiovisual y ficción televisiva, with Jesús Martín-Barbero; Industrias culturales, creatividad y desarrollo, Balsas y Medusas, about politics in the media, and Desde las dos orillas, about the right to information.

Keywords: Germán Rey; culture; communication; journalism; digital media.

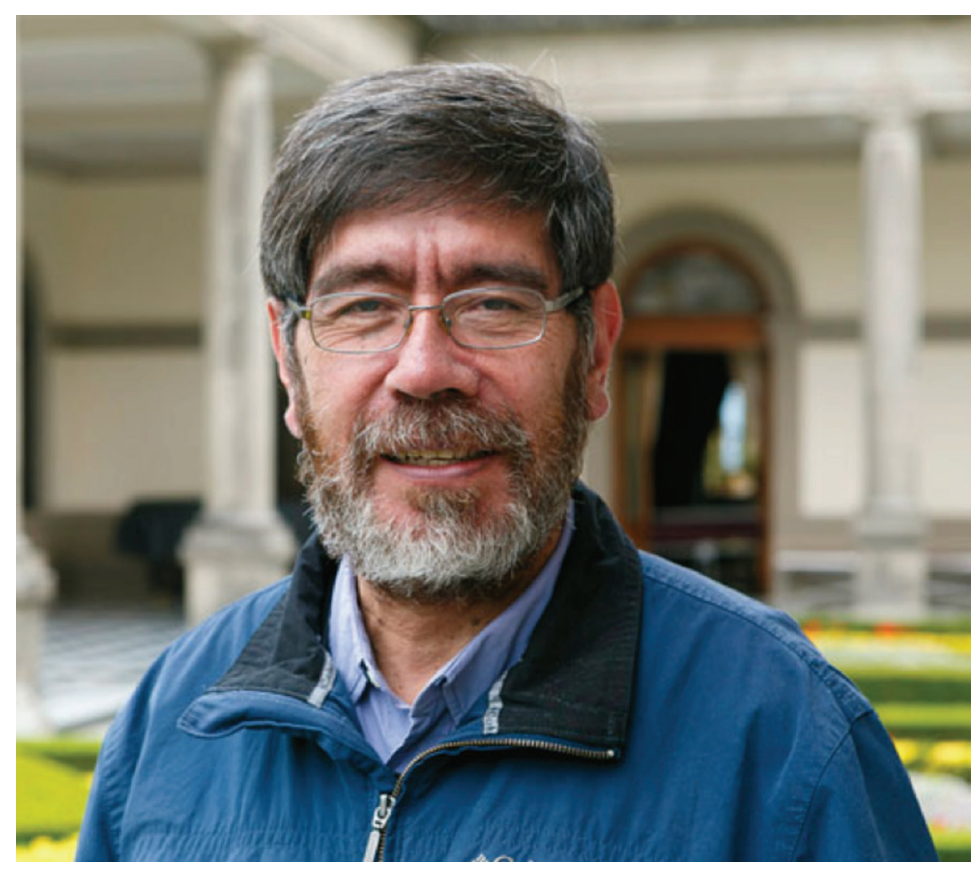

Germán Rey é professor, pesquisador e milita por cultura, comunicação e jornalismo na Colômbia

Comunicação $\mathcal{E}$ Educação: Professor, como a cultura pode ser constituída em um espaço de resistência e expressão política, quando a política não realiza sua tarefa de representar e organizar pessoas?

Germán Rey Beltrán: A crise da política não é apenas profunda, mas tem múltiplos rostos. Para onde quer que se olhe, a política está presente; seja em seus modelos de representação ou na identidade de suas organizações partidárias, em suas conexões com a sociedade ou em suas formas internas de coesão. E tudo isso não escapa às relações entre comunicação e política que eram de 
um modo na era da mídia e se modificaram em tempos de internet, redes sociais e no novo ambiente digital. A mídia se tornara um dos principais espaços da cena política, assim era possível a publicação, a construção mais ou menos racional de agendas, acordos sobre interpretação de informações eleitorais e a distribuição mais ou menos equilibrada de espaços de opinião. Mas tudo isso mudou no ambiente digital: a profusão de notícias políticas cresceu enquanto a rede de fake news cresceu, assim como distorções intencionais e uma enorme pressão sobre os políticos.

A cultura sempre teve entre suas características o fato de ser um ponto de resistência, e também é cada vez mais um campo de direitos, tensões e expressividade, contudo não acho que seja chamada a substituir a política, mas para dar novos significados ao exercício da política, especialmente em tempos de crescente desconfiança e ceticismo dos cidadãos. Um fato muito interessante foi a mobilização de diferentes setores da cultura quando o atual governo tomou como uma de suas primeiras medidas a supressão do Ministério da Cultura. Não se pode suprimir o que se tornou capital simbólico de cidadãos e cidadãs.

Figura 1: Industrias culturales, creatividad y desarrollo, de Gérman Rey, 2009

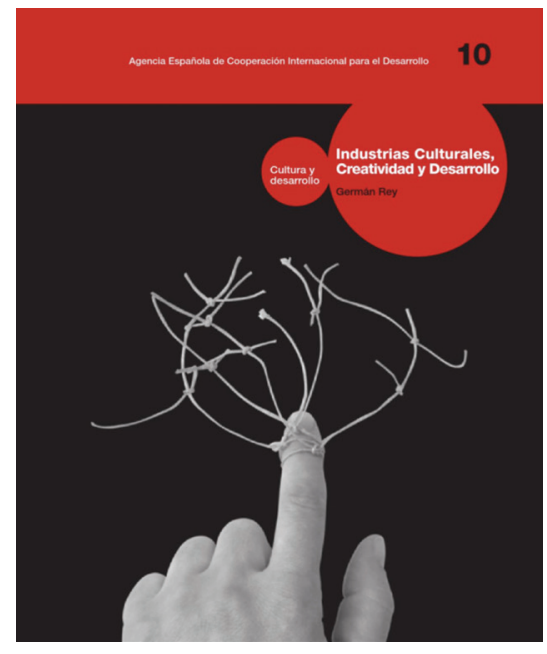

$C \mathcal{E}{ }^{2} E$ : Todos sabemos que as estratégias dos países hegemônicos em nossa região, após a guerra fria, são definidas pelas ações do soft power. Hoje, esses instrumentos são muito mais sofisticados e, portanto, ainda mais poderosos. Como o senhor analisa a cultura usada como um campo de intervenção do soft power?

GRB: O soft power foi aplicado especialmente à diplomacia cultural, isto é, o intercâmbio intercultural como estratégia de posicionamento nas relações internacionais. A diplomacia concentrou-se - e segue concentrando-se - nas relações políticas e econômicas, mas pouco a pouco foram sentidos os choques culturais e as transformações da cultura como elementos centrais da geopolítica. O primeiro é expresso nas diásporas migratórias, nas tensões decorrentes das compreensões e práticas religiosas, fraturas éticas produzidas 
pela secularização e também pelas mudanças nas relações humanas; a segunda, pelo papel da cultura na definição progressiva das identidades nacionais ou a globalização da cultura, como afirmou em seu tempo o investigador brasileiro Renato Ortiz. Se os países hegemônicos exercem influência por meio das manifestações da cultura global - como o cinema ou o design, a televisão ou a música que circula universalmente -, os países periféricos fazem esforços para serem reconhecidos e diferenciados internacionalmente por meio de características culturais como o cinema iraniano, o vídeo nigeriano ou a música colombiana, mas também por meio de fenômenos muito interessantes de fusões e misturas.

CEEE: No livro Os exercícios do ver, de sua autoria com Jesús Martín-Barbero, traduzido em 2001 para o português brasileiro, encontramos na introdução um trecho emblemático:

“...mais que uma enfermidade da política, a mídia de massa televisiva indica a direção da crise de representação e as transformações que está atravessando a identidade da mídia. $E$ isso por causa das rupturas vividas pelo espaço audiovisual em seus ofícios e alianças, em suas estruturas de propriedade e gestão, e nas reconfigurações do discurso televisivo". Com base nisso, pergunto: quais reconfigurações e transformações estão acontecendo hoje nas mídias por causa dos meios digitais e dos aparelhos celulares?

Figura 2: Os exercícios do ver, obra conjunta de Jesús Martin-Barbero e Germán Rey, 2001

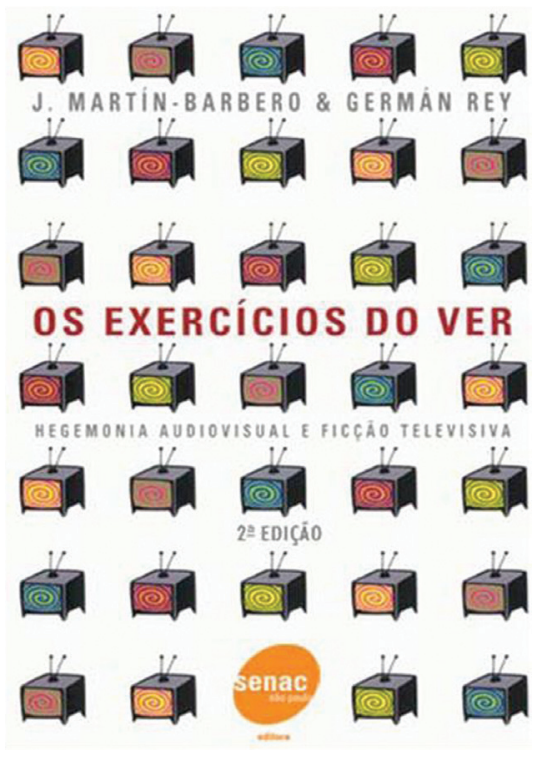

1. MARTIN-BARBERO, J.; REY, G. Exercícios do ver. São Paulo: Senac, 2001.
GRB: Depois que fizemos esse livro com Jesús Martín-Barbero, muitas coisas aconteceram no campo da cultura e, particularmente, no desenvolvimento da mídia. Eu costumava escrever sobre TV e sempre estava interessado em ver o país - Colômbia - a partir de suas transformações. Não só a partir das transformações regulatórias, que foram muitas e muito interessantes - pois nelas se expressavam a política e, em geral, o poder -, ou de suas modificações 
tecnológicas, mas sobretudo pela perspectiva de suas narrativas sobre o país e os processos de apropriação social e simbólica do público. Porém, desde 2000 meu foco mudou para indústrias criativas e novas tecnologias, tanto conceitual como profissionalmente, porque durante cinco anos dirigi um grande laboratório de tecnologia para as artes e novas formas de expressão (plataformas, videogames, aplicativos, educação virtual, arquiteturas efêmeras ou design). Foi muito interessante participar inicialmente da pesquisa sobre um meio tradicional como a televisão e, em uma continuação muito sugestiva, atuar no mundo digital aberto. Em primeiro lugar, os tempos de constituição desses meios mudaram radicalmente. A televisão na Colômbia passou pelo menos 30 anos se consolidando como o meio de massa que é ainda hoje embora é possível que não mantenha essa condição por muitos anos -, enquanto a internet, os computadores e especialmente a telefonia móvel foram mais rápidos para alcançar essa posição, sobretudo os celulares, que excedem a quantidade de habitantes do país. Em segundo lugar, os meios tradicionais conseguiram projeção pela penetração do digital não só no âmbito tecnológico, mas também em seus modelos de negócios, no teor de seus relatos e em suas formas de apropriação cultural. A circulação dos jornais impressos e das revistas tem decaído, a dos livros cai vertiginosamente, o rádio analógico tem cedido seu espaço ao digital e a televisão aberta está cheia de incertezas e atribulações. Boa parte de seu futuro está em situação diferente no universo digital, que faz que a mídia seja reestruturada não só econômica mas também imaginativamente, isto é, por sua presença na sociedade, seu caráter político e significado cultural.

Segui com muito interesse o que acontece com os celulares. As primeiras pesquisas nacionais das quais participei sobre a cultura digital mostraram sua incidência não apenas nas classes média e alta, mas também nas populares que se conectam à internet e adquirem informação pelo uso de smartphones. Nos setores populares, a telefonia fixa deixou de existir para ser eficientemente substituída pela telefonia móvel. A exclusão digital, que tem sido discutida há anos, tende a diminuir entre os moradores urbanos, ao menos pelo que observei na Colômbia, enquanto ainda é pronunciada nas áreas rurais e nos pequenos municípios.

Algo muito interessante nos celulares é a geografia das funções que as pessoas encontram em seus aparelhos, que tem relação com se comunicar, entreter-se e com o acesso à informação. O aparelho celular é hoje um dos dispositivos culturais mais interessantes; por ele se dão os downloads e o recebimento de músicas, a conexão com a informação, a construção de um novo horizonte visual por meio das fotografias, dos álbuns virtuais, das selfies ou de sua incorporação aos textos de bate-papos e às timelines do Facebook, além do acesso a vídeos e às novas formas de escrever e ler. Roger Chartier nos lembra que "a revolução digital do nosso presente modifica tudo de uma vez, os suportes para a escrita, a técnica de sua reprodução e disseminação e as formas de leitura. Essa simultaneidade é sem precedentes na história da humanidade"².
2. CHARTIER, R. Promesas digitales. Palestra "Aprenda a ler, ler para aprender", ministrada na Unidade de Seminários do Fundo de Economia da Cultura. México, junho de 2008. p. 1. 
Estou muito interessado em alguns fenômenos, como a construção da memória em algo aparentemente evanescente e episódico (internet), a mente tecnológica sem tecnologias e as articulações nas áreas rústicas do conhecimento popular sobre a terra, o clima ou a astronomia com novas tecnologias. Também estou interessado na expansão do laboratório não só como um espaço, mas como uma prática cultural e maneira de proceder que as novas tecnologias introduziram nos comportamentos atuais e cotidianos.

$C \mathcal{E}{ }^{2} E$ : Sua experiência como assessor no Ministério da Cultura na Colômbia, na primeira década dos anos 2000, certamente proporcionou uma ótima visão sobre a diversidade colombiana. Como o senhor vê essa relação complexa entre o nacional e o popular, ou, dito de outra forma, a expressão de muitas nações em um único Estado Nacional?

GRB: Eu era, de fato, assessor de Políticas Culturais da Ministra da Cultura Paula Marcela Moreno Zapata. Um dos trabalhos que ela promoveu e que eu coordenei foi a elaboração do compêndio das políticas culturais da Colômbia, talvez um dos poucos cartogramas existentes no continente sobre o assunto. Contudo, não foi apenas um exercício de memória, mas uma experiência muito emocionante devido a sua diversidade em vários sentidos, pela multiplicidade de entendimentos sobre o que é uma política pública, pela variedade dos temas que compõem o cânone da gestão pública na cultura e pela heterogeneidade da sociedade que foi revelada nesses entendimentos. Quanto à primeira colocação, gostaria de comparar os textos pioneiros de Néstor García Canclini sobre esse assunto com seus textos mais recentes. Na década de 1970, ele falou de política como meio de estabelecer ordens, enquanto atualmente se refere a ela como conversas. Essa é uma mudança fundamental, porque as políticas culturais, assim como as políticas públicas em geral, deixaram de ser da alçada dos Estados Nacionais, regionais ou mesmo locais, para se tornarem diálogos muito mais complexos e estimulantes entre Estado, sociedade civil, organizações sociais, criadores e artistas, instituições culturais e, obviamente, movimentos de resistência que são críticos não só à forma como as políticas são formuladas ou implementadas, mas também ao próprio conceito de política, considerado muito unilateral e rígido.

A diversidade temática é impressionante. Porque olhar para as políticas culturais de um país ou de uma cidade é perceber a intensa variedade dos campos da cultura, desde as artes até o patrimônio imaterial, desde a promoção e a participação até a educação artística, o turismo ou a comunicação cultural. E esses campos não são vistos apenas em si mesmos, de forma isolada, mas como um tecido denso, uma urdidura, seja com o cultural ou com os outros territórios da vida social, desde o meio ambiente à saúde, à educação ou à economia.

E, acima de tudo, está a diversidade do país. Observar essas coisas em um país com um conflito de décadas, de enormes desigualdades e de regiões muito diferentes é algo que surpreende; assim como fazê-lo por meio da diversidade de suas comunidades étnicas, afro-colombianas e raciais ou das lutas identitárias 
das populações LGBTI. Entre outras possíveis explorações, navegando por nessa diversidade, estão as que contrastam o nacional, o regional ou o popular com as classes médias emergentes da pobreza. Elas testam a noção de Estado Nacional do século XIX para afirmar nações que são descobertas e construídas através de afirmações locais, de suas vidas mais íntimas, de suas identidades em formação e em permanente ebulição. Nós fomos estados unidos administrativamente e politicamente, mas não estados que se enriquecem com essa diversidade e com os conflitos que a própria diversidade gera. Não se trata de uma visão ingênua sobre a diversidade, mas de uma visão feita de isolamentos e de algumas formas de encontro, de histórias com marcas regionais e relatos - relativamente frágeis - em que todos nos reconhecemos.

Uma das questões que persistiram nessa discussão foi a relação entre a nação territorial e unificada, porque as políticas culturais tendem a ser tremendamente setoriais e descendentes, quando deveriam buscar se articular e serem ascendentes.

CEEE: Esses confrontos políticos entre o Estado nacional e a diversidade cultural da população estão na mídia?

GRB: Sim. E faz muito tempo. De uma maneira diferente em jornais, rádio e televisão. Os jornais têm sido fortemente centralistas, sejam nacionais ou locais. Existe uma centralidade geográfica, mas, sobretudo, política, social e cultural. Política porque foram intérpretes ideológicos de partidos políticos por décadas, pelo menos; social porque estavam centrados nos letrados, que tiveram acesso à educação, e naqueles que, pela própria perspectiva, "geravam opinião", ou seja, os políticos, o governo, os empresários e alguns educadores - neles e, é claro, em suas prioridades, prevaleceram seus discursos e seus horizontes de interpretação; e cultural porque sua visão de cultura era quase sempre singular, enfatizando as chamadas "culturas cultas" e desprezando as culturas populares. As culturas de massa entraram na imprensa escrita quando a cultura se tornou indústria e, acima de tudo, entretenimento. Há, claro, exceções honrosas.

$\mathrm{O}$ rádio na Colômbia foi um meio fundamental para colocar as culturas populares em cena, especialmente por meio da música, dos esportes, do rádio e da televisão e pela informação, que apareceram junto dos processos de modernização que ocorreram na primeira metade do século XX. E a televisão foi uma oportunidade para a circulação da diversidade cultural, apesar de suas distorções e restrições. A telenovela foi, sem dúvida, um gênero e um formato televisivo que possibilitou, na Colômbia e em outros países da região, as disputas de gosto, o reconhecimento de um país ausente, o tom expressivo das regiões e a educação sentimental e conceitual sobre vários assuntos que a modernidade estava introduzindo em outras frentes e por meio de outras instituições.

$C \mathcal{E} E$ : O senhor é professor de cursos de jornalismo e coordenou uma pesquisa sobre jornalismo digital na Colômbia. $\mathrm{O}$ que pode falar sobre isso? 
GRB: Cheguei ao jornalismo de pelo menos duas maneiras: escrevendo e analisando as representações midiáticas. Ter estado muito próximo da Fundação Gabriel García Márquez do Novo Jornalismo me abriu outros campos de ação: a promoção do jornalismo e a formação de jornalistas. Alguns anos atrás, fiz dois estudos sobre mídia digital informativa na Colômbia. Era como estudar um objeto em meio a seu próprio big bang. Uma vez eu disse que tinha que contradizer o que meus professores me ensinaram na Universidade Nacional quando nos contaram sobre metodologias de pesquisa nas ciências sociais com as quais o estudioso poderia abordar objetos disciplinares relativamente estáveis apesar de seus movimentos mais ou menos constantes. Quando estudei mídias digitais, tive uma experiência diferente. Primeiro, não havia uma cifra concreta sobre a quantidade de mídias digitais que existiam no país naquela época, e, inclusive, havia pouca consciência de que elas existiam. Claro que não se trata da mídia digital nacional, quase sempre de jornais conhecidos, mas os pequenos meios que estavam partindo da internet para os lugares mais diferentes do país. Pois bem, a primeira coisa que me surpreendeu foi a quantidade e a capacidade de reprodução. Entre um ano e outro dos meus estudos, o meio digital duplicou, indo de 350 a 700 nas regiões compreendidas desde Putumayo até La Guajira. O segundo é que alguns deles apareceram e desapareceram durante o tempo de estudo. Essas são pequenas experiências, com um pequeno número de colaboradores, que migraram de outros meios de comunicação tradicionais, embora alguns já sejam totalmente nativos digitais. Eles geralmente pegam informações que circulam na web, mas também têm uma porcentagem relevante de informações próprias que começam a se posicionar em redes e a fazer um jornalismo de proximidade com suas comunidades de origem. Nós temos que estudá-los muito, interagir com eles com mais frequência porque eles nos levarão a encontrar surpresas importantes. Em síntese: há uma nova geografia imaginária que está dispersa em todo o país e que constitui nós fundamentais de circulação das manifestações culturais, da informação e da opinião.

$C \mathcal{E}^{\circ} E$ : $\mathrm{O}$ jornalismo é um discurso que nasce com a modernidade industrial. Mas em nossas sociedades sempre esteve na marcha ré da ficção, e, acima de tudo, do melodrama. Há muitos apelos para ele: como jornalismo de dados; fake news; pós-verdade, então, hoje, com todas as possibilidades produtivas da mídia móvel, o que acontece com o jornalismo?

GRB: Em 1996, escrevi um livro sobre jornalismo no qual, por meio de dados estatísticos, duvidava de que os jovens lessem jornais. Mas o mais grave não era isso: tudo fazia supor que eles também não leriam no futuro. Nós já estamos vivendo nesse futuro e a hipótese do passado é uma realidade no presente. Tive a oportunidade de colaborar com Gabriel García Márquez por vários anos e pude ver nele a viva relação entre ficção e jornalismo. Essas duas dimensões eram inseparáveis: ele costumava dizer que por trás de seu trabalho como escritor estava sua formação em pesquisa jornalística. 
Esse é, sem dúvida, um tema muito interessante. Perguntar sobre as relações entre ficção e jornalismo na modernidade cultural. Muitos movimentos culturais foram testemunhados em jornais que, por exemplo, desempenharam um papel central na difusão da literatura e dos escritores. Uma boa parte dos escritores latino-americanos eram, ao mesmo tempo, jornalistas de opinião ou até repórteres e cronistas. Para alguns, incluindo, claro, García Márquez, o jornalismo é um gênero literário. O rádio facilitou a divulgação cultural e a participação de poetas, artistas e literatos em programas de opinião. Mas talvez a televisão tenha sido o meio que mais envolveu a cultura em sua linguagem e formato, através do melodrama, mas também das séries e da comédia. O primeiro trabalho colombiano para televisão não foi outro senão O processo de Kafka. Veja a que ponto chega o atrevimento dos colombianos! Mas a relação entre literatura nacional, latino-americana e telenovela é fundamental.

Fui várias vezes júri do Prêmio Gabriel García Márquez do Novo Jornalismo, uma janela insuperável para se ver o desenvolvimento do jornalismo e da mídia em espanhol e português, ou português brasileiro. Mas o que acontece com o jornalismo? Muitas coisas. Afirmam-se valores originais do jornalismo, como contar histórias, investigar, proceder com rigor e precisão, deliberar e tentar pôr em prática uma atitude ética consistente no jornalismo. Existe um interesse na qualidade jornalística e um risco ao buscar novas formas de narrar em multitelas e em novos suportes digitais. Há experiências muito valiosas de mineração de dados; visualizações ousadas além do campo desenhado pela infografia; fusão de diversas linguagens (texto escrito, animação, quadrinhos, vídeo, música); funções jornalísticas, como a verificação de informações emitidas pelos influenciadores; trabalho colaborativo jornalístico envolvendo jornalistas de diferentes países; elaboração de prioridades ascendentes com participação pública; renovação às vezes irônica e lúdica da opinião pública tão rígida e pontifical; do surgimento de grupos autônomos de produção de conteúdos; de meios com maior independência do capital econômico ou dos políticos habituais. Eu vi portais especializados em questões sociais, em informações políticas, em uma gestão econômica diferente do que estávamos acostumados; observei um crescimento de livros jornalísticos dedicados à crônica. Em resumo: o que eu vejo é uma vida muito ativa, inspiradora e esperançosa no jornalismo latino-americano.

CEE E: Em muitos países da América Latina, a profissão de jornalista é uma ameaça à vida. $O$ que o Estado pode fazer para gerar políticas públicas de segurança ao profissional?

GRB: Entre 1977 e 2015, 152 jornalistas colombianos foram mortos por causa de sua profissão. A cifra é uma das mais altas nos registros mundiais desse período. Entre 1986 e 2004, a Colômbia ficou nos primeiros lugares na lista global de crimes contra jornalistas, ao lado do Afeganistão, Iugoslávia, Rússia, Iraque e Serra Leoa ${ }^{3}$. Entre 1986 e 1995, 61 jornalistas foram assassinados na Colômbia e, na década posterior, entre 1996 e 2005, morreram outros

3. Estatísticas por ano do Committee to Protect Journalist disponíveis em: <https://cpj.org/>. Acesso em: 27 set. 2017. 
60 , somando o total de 121. Isso significa que, apenas nesses 20 anos, foram assassinados $78 \%$ do número total de jornalistas que morreram exercendo seu ofício em 40 anos.

Eu era o coordenador e relator do informe do Centro Nacional de Memória Histórica da Colômbia, "A palavra e o silêncio: violência contra jornalistas na Colômbia, 1977-2015”, em que tentamos explicar o que aconteceu nesses anos. Um dos capítulos é dedicado a reconstruir as ações tanto do Estado como da sociedade e dos próprios jornalistas para conquistar a segurança dos jornalistas e da mídia. Entre tanta barbárie surgiram projetos e experiências de solidariedade verdadeiramente exemplares. Gerou-se uma ampla rede de alerta e proteção de jornalistas apoiada pelo Estado e pelas organizações jornalísticas; promoveu-se o maior desenvolvimento das instituições para a defesa da liberdade de expressão; foram criadas associações de jornalistas nas regiões; programas de formação foram estendidos; publicações e acompanhamento das realidades do jornalismo no país foram ampliados. Também tem sido fundamental a participação de muitas organizações internacionais, bem como da cooperação. E embora o futuro ainda tenha muitas sombras para o exercício do jornalismo na Colômbia, prevalece a coragem e o empenho de muitos meios de comunicação e comunicadores, assim como a solidariedade nacional e internacional em relação à crueldade e aos atos violentos.

4. O Centro Nacional de Memória Histórica da Colômbia é coordenado por Gonzalo Sánchez Gómez, diretor-geral, e o informe foi relatado por Germán Rey e publicado em 2015, Bogotá.

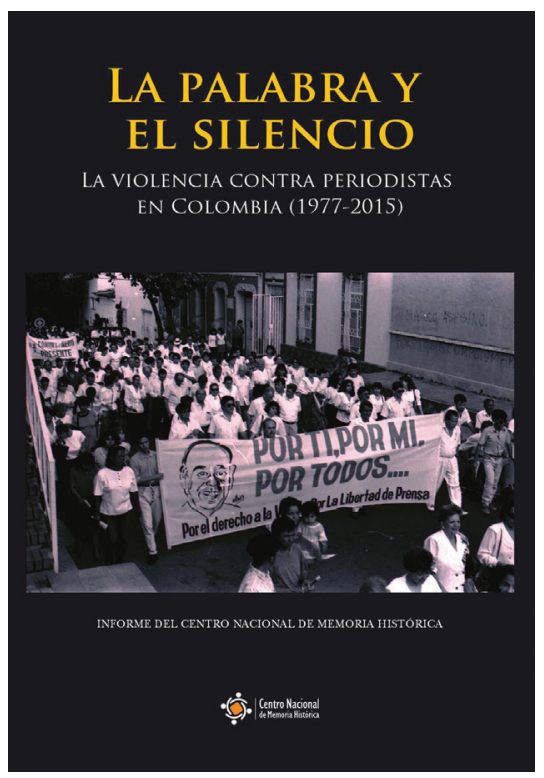

Figura 3: Germán Rey foi o relator do informe sobre a violência contra os jornalistas na Colômbia entre 1977 e 2015

$C \mathcal{E}{ }^{2} E$ : As políticas de comunicação e educação são frequentemente usadas como disseminadoras de bens tecnológicos; outras vezes são instrumentais, com o objetivo de preparar mão de obra adequada para as mudanças de mercado, especialmente o que trata da polivalência e do profissional multiplataformas. Como isso ocorre na Colômbia? 
GRB: A contrição sincera e os propósitos de emenda não são duas características dos mercados. A situação dos profissionais de tecnologia na Colômbia não é muito diferente da de outros países. Além disso, a realidade da penetração de tecnologias em todos os campos da vida social, a mudança da realidade analógica para a realidade digital e a fusão entre empresas de conteúdo e empresas de tecnologia têm um forte viés instrumental e econômico. Muitas vezes eu ouvi dizer que o número de pessoas treinadas para enfrentar mudanças tecnológicas ainda é muito baixo, com ênfase no treinamento técnico; mas raramente ouvi falar da necessidade de entender essa mudança do interesse público e da sociedade.

CEEE: As diretrizes dos órgãos de governança internacional produziram relatórios e orientações sobre Mídia Educacional ou Mídia para Alfabetização, uma plataforma única de orientação para todos os continentes, inclusive a África. $O$ que acha dessas práticas?

GRB: Eu amo plataformas, mas não no singular, no plural. $\mathrm{O}$ avanço tecnológico tem sido acompanhado de certa metáfora desproporcional e um tanto obscena do pensamento universal como único, quase canônico e totalizante. Isso me lembra algo que eu li certa vez em J. F. Lyotard referindo-se à passagem, na teoria do conhecimento, da metáfora do relógio à metáfora das nuvens. Não há maior soberba, dizia, do que pensar em um sistema totalizador das nebulosidades. A biblioteca universal ou uma plataforma única de orientações para a Mídia de Alfabetização são, até certo ponto, figurações soberbas. O que precisamos é uma ampla, plural e diversificada oferta de opções que dialoguem criativamente com as realidades locais e circulem em espaços abertos, colaborativos e moleculares.

$C{ }^{2} E$ : Para terminar, pode nos contar o que tem publicado e planejado recentemente?

GRB: O texto mais recente que escrevi é uma reflexão sobre a nova imaginação do museu, a biblioteca e o laboratório que o Itaú Cultural divulgará. $\mathrm{O}$ informe citado sobre a violência contra jornalistas na Colômbia foi muito divulgado e alguns textos mais extensos esperam, em repouso, ser publicados. É uma espécie de homenagem a um aviso gigantesco que foi pintado na parede de uma empresa de tabaco em Bucaramanga, a cidade onde nasci, e que dizia: "Silêncio, tabaco em repouso". Os livros necessitam de silêncio e repouso. E assim temos um livro sobre a leitura, outro sobre políticas culturais e um texto que escrevi faz tempo, intitulado "O país da ficção: gêneros televisivos e mudanças na sociedade”. Em repouso. 
